\title{
New Innovative Method in the Field of Social Choice Theory
}

\author{
Zoïnabo Savadogo ${ }^{1}$, Sougoursi Jean Yves Zaré ${ }^{1}$, Wambie Zongo ${ }^{1}$, Somdouda Sawadogo ${ }^{2}$, \\ Blaise Somé ${ }^{1}$ \\ ${ }^{1}$ Laboratory of Numerical Analysis of Computer Science and Biomathematics (LANIBIO), Joseph Ki-Zerbo University, Ouagadougou, \\ Burkina Faso \\ ${ }^{2}$ Institute of Sciences, Ouagadougou, Burkina Faso
}

\section{Email address:}

serezenab@yahoo.fr (Z. Savadogo), sougoursi@hotmail.com (S. J. Y. Zaré), excellence.2012g@gmail.com (W. Zongo), sawasom@yahoo.fr (S. Sawadogo), blaisesome@gmail.com (B. Somé)

\section{To cite this article:}

Zoïnabo Savadogo, Sougoursi Jean Yves Zaré, Wambie Zongo, Somdouda Sawadogo, Blaise Somé. New Innovative Method in the Field of Social Choice Theory. Pure and Applied Mathematics Journal. Vol. 10, No. 6, 2021, pp. 121-126. doi: 10.11648/j.pamj.20211006.11

Received: October 22, 2021; Accepted: November 19, 2021; Published: November 27, 2021

\begin{abstract}
Social choice theory includes the study of voting methods. In the literature on social choice theory many methods exist, the main objective of all these methods is the determination of a good method. However, many of these methods give controversial results which often lead to disputes. It should also be noted that sometimes, regardless of the method used, there are people who are not ready to accept the results given by the ballot box. The ideal would be to find a method with good properties, because it seems that there are no completely satisfactory methods. Since the goal of a voting method is to reconcile several points of view into a general interest, one should focus on the properties. The geometric mean does not lead to a compensation of weak criteria by stronger ones as it is the case with the arithmetic mean. Indeed, by using the geometric mean, even if only one criterion is very weak and the others are very strong, a candidate may not be well ranked; moreover, assent voting is very well appreciated in the literature by many authors and also generates huge opportunities. This justifies our choice in this work to combine geometric mean and assent voting to develop a method with good properties.
\end{abstract}

Keywords: New Method, Innovative, Social Choice Theory

\section{Introduction}

Literature is well supplied with many voting methods. In the group decision, several procedures have been proposed to determine, from individual preferences, a collective preference [7].

But until then it is difficult to say that this or that other method is totally satisfactory. According to Antoinette BAUJARD and al [2], a voting system must, as a matter of priority, best reflect the preferences of voters. Several criticisms are therefore made of these methods of voting by theoreticians of social choice and especially in relation to the controversial results they generate. Thus according to Michel TRUCHON [9], there is an abundant literature on the aggregation of individual preferences into collective preference on the difficulties posed by this problem and on the strategic manipulation of social choice procedures as well.

Many writers have questioned the majority system, which seems to give sometimes surprising results.
Thus in "Rapport public du Centre dŠAnalyse Stratégique. 2007" [2], it appears that the ordinal approach of individual preferences, formerly dominant in social choice theory, is now disputed by authors such as Hillinger [15] and Balinski and Laraki [13]

According to the same source, these authors reject classification voting systems and propose aggregation methods based on the evaluation principle.

According to Hatem SMAOUI and Al [3] classification voting systems use ordinal preferences of voters and that this ordinal context does not make it possible to judge (or appreciate) the different options independently.

According to Jorge GONZALEZ SUITT and Al [6], the one or two-round majority voting system has a large number of widely known and proven defects. the desire to find a voting system reflecting popular interest seems to be a great general concern. Assent voting is a method with good properties according to the literature. It allows each voter to assess all candidates. 
The elector is not restricted to voting for a single candidate. He may choose or, approve, several candidates, all or none if he wishes; but he can not vote several times for the same candidate. The winner is the candidate who has received the most approvals. This type of ballot, though simple, verifies properties very interesting and shows in many points superior to the majority vote [10]. Equally, approval voting can be defined as a procedure where each voter has the opportunity to express a cardinal preference in awarding a mark of one point to each candidate he or she supports and zero points to all others [2]. In addition to [4], approval voting is used during the selection of candidates for the position of Secretary-General of the United Nations Security Council and the Latvian parliamentary elections also draw inspiration from it. Authors such as Patrick Blanchenay in [10], Antoinette Beaujard and al in [1] appreciated the vote by assent.

Thus in this work, we are inspired by the assent and the geometric mean, to contribute to the literature a satisfactory method.

\section{State of the Art}

\subsection{Desirable Properties for a Voting System}

A voting system must satisfy certain principles. According to Michel BALINSKI, Rida LARAKI [8] the most basic are:

1) Treat candidates and voters fairly.

2) Elect a candidate unanimously preferred by all voters.

3) Designate a winner (except rare equivals).

4) Keep the winner in the presence or absence of another candidate.

\subsection{Description of Majority Judgment}

This section is from [11]

Balinski and Laraki adopted, in their 2007 experience in the French presidential elections, the following common language:

\{Excellent, Very good, Good, Fairly, Fair, Insufficient, Refuse\}

We call common language a set $\mathrm{L}=\left\{g_{1}, g_{2}, \ldots, g_{k}\right\}$ strictly ordered by " > " such as

$$
g_{1}>g_{2}>\ldots>g_{k}\left(g_{i}>g_{j}=g_{i}>g_{j} \text { or } g_{i}=g_{j}\right) .
$$

Note that we can also have a common language be an infinite set such as the interval $[0,1]$ of real numbers with its natural order.

Note the possibility for a voter to assign the same assessment to more than two candidates. As such, a voter may award a $A$ candidate the VG score, a $B$ candidate the VG note and another $C$ candidate the note.G. In the context of arrow, we will say:

" $A$ is at least as good as $B$ ", " $B$ is at least as good as $A$ ", " $A$ is at least as good as $C$ ", " $B$ is at least as good as $C$ ", " $A$ is preferred to $C$ ", " $B$ is preferred to $C$ ", " $A$ is indifferent to $B "$.

A function $F$ is a ranking method if it associates to any profile a single rank [in the same language] for any candidate. So,

$\mathrm{F}: L^{m \times n} \quad L^{m}$

Where $m$ is the number of candidates, and $n$ the number of judges or voters.

Let $A_{i}$ be a candidate or competitor with grades $g_{i 1}, g_{i 2}, \ldots, g_{i n}$ where $g_{i 1}>g_{i 2}>\ldots g_{i n}$. Then the majority or majority grade $\mathrm{f}^{\mathrm{maj}}\left[\mathrm{A}_{\mathrm{i}}\right]$ is by definition:

$$
f^{m a j}\left(A_{i}\right)=\left\{\begin{array}{l}
f^{\frac{n+1}{2}}\left(g_{i 1}, g_{i 2}, \ldots, g_{i n}\right) \text { if } n \text { is odd } \\
f^{\frac{n+2}{2}}\left(g_{i 1}, g_{i 2}, \ldots, g_{i n}\right) \text { if } n \text { is peer }
\end{array}\right.
$$

For example, if 5 judges award grades 4, 8, 7, 9, 5 à $A_{i}$,

$$
f^{m a j}\left(A_{i}\right)=f^{3}(9,8,7,5,4)=7
$$

And if 8 judges award grades 9, 7, 3, 6, 5, 4, 5, 8 à $A_{i}$,

$$
f^{\text {maj }}\left(A_{i}\right)=f^{5}(9,8,7,6,5,5,4,3)=5
$$

\section{TIE-BREAKING [13]}

When the majority grades of two candidates are different, the one with the highest rank is ranked before the other. The majority ranking $>_{\text {maj }}$ between two candidates evaluated by the same jury is determined by a repeated application of the majority rank:

1) If $f^{\text {maj }}(A)>f^{\text {maj }}(B)$ so $A>$ maj $B$

2) If $f^{\text {maj }}(A)=f^{\text {maj }}(B)$ then a grade is rejected from the list of grades of each candidate and the procedure is repeated.

M. Balinski \& R. Laraki (2010). [12] give this example to illustrate their definition:

Suppose $A$ and $B$ are evaluated by a 7 voting jury:

Table 1. Voting score.

\begin{tabular}{llllllll}
\hline $\mathrm{A}$ & 85 & 73 & 78 & 90 & 69 & 70 & 73 \\
$\mathrm{~B}$ & 77 & 70 & 95 & 81 & 73 & 73 & 66 \\
\hline
\end{tabular}

The ordered profile is:

Table 2. Ranked voting score.

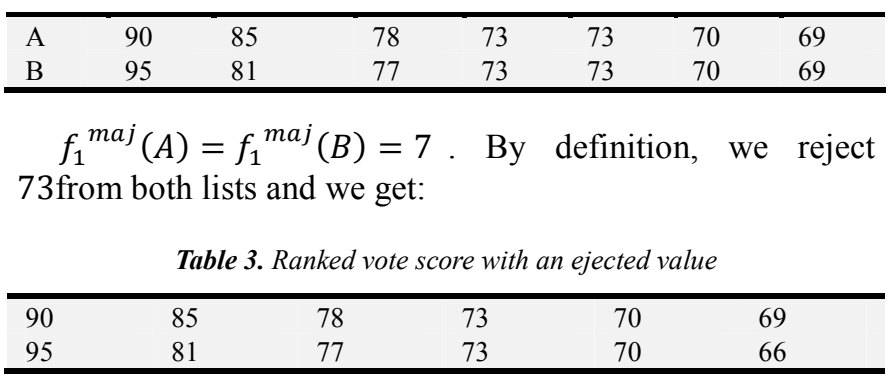

$f_{2}{ }^{m a j}(A)=f_{2}{ }^{m a j}(B)=73$. By definition, we reject 73 from both lists and we get:

Table 4. Vote score stored with another value ejected.

\begin{tabular}{llllll}
\hline $\mathrm{A}$ & 90 & 85 & 78 & 70 & 69 \\
$\mathrm{~B}$ & 95 & 81 & 77 & 70 & 6 \\
\hline
\end{tabular}

$$
f_{3}{ }^{m a j}(A)=78>f_{3}{ }^{m a j}(B)=77 \text {. Since then, } A>_{m a j} B \text {. }
$$


It is clear that the majority position always ranks one candidate before the other unless the judges give them the same rank.

In case there are several judges or voters [presidential elections for example], Balinski and Laraki present a way of dealing with tie-break.

The majority of a candidate with $f^{m a j}(A)=\alpha$ is a triplet $\left(p_{A}, \alpha^{*}, q_{A}\right)$ or $p$ is the number or percentage of the candidate's ranks that are greater than the majority rank, $q$ is the number or percentage of the candidate's ranks that are less than the majority rank, and $\alpha^{*}=\alpha^{+}$if $p>q$ and $\alpha^{*}=\alpha$ if $p 6 q . \alpha^{*}$ is called the modified majority rank of the candidate.

By definition, $\alpha^{*}>\beta^{*}$ if and only if $\alpha>\beta$ or $\left(\alpha=\beta\right.$ and $\alpha^{*}=$ $\alpha^{+}$and $\beta^{*}=\alpha^{-}$). Balinski and Laraki use majority Gauge to define majority ranking $>_{m g}$.
Let $A$ and $B$ two candidates with respective majority gages $\left(p_{A}, \alpha_{A}{ }^{*}, q_{A}\right)$ and $\left(p_{B}, \alpha_{B}{ }^{*}, q_{B}\right)$

So $A>_{m g} B$ or $\left(p_{A}, \alpha_{A}{ }^{*}, q_{A}\right)>_{m g}\left(p_{B}, \alpha_{B}{ }^{*}, q_{B}\right)$ ssi $\alpha^{*}>\beta^{*}$ or $\left(\alpha_{A}^{*}=\alpha_{A}^{*}=\alpha^{+}\right.$et $\left.p_{A}>p_{B}\right)$ or

$\left(\alpha_{A *}=\alpha \alpha^{*}=\alpha\right.$ - et $\left.p_{A}<p_{B}\right)$.

Manzoor Ahmed Zahid [14] shows that ranking by majority can not decide between candidates in some cases. A theorem uttered by Balinski and Laraki (Theorem 14.1 in [12]) shows that:

$$
\mathrm{A}>_{\mathrm{mg}} \mathrm{B} \Rightarrow \mathrm{A}>_{\mathrm{maj}} \mathrm{B}
$$

Ahmed Zahid then takes an example that illustrates a case where $A>_{m g} B$, but neither

$$
\text { B }>_{\text {maj }} \text { A ni B }>_{\text {mg }} \text { A. }
$$

\begin{tabular}{|c|c|c|c|c|c|c|c|c|c|}
\hline Candidate & $\mathbf{p}$ & Excellent & Very good & Good & Pretty good & Fair & A Reject & $q$ & Total \\
\hline A & 5 & 2 & 3 & 3 & 1 & 3 & 3 & 7 & 15 \\
\hline B & 6 & 3 & 3 & 2 & 0 & 2 & 5 & 7 & 15 \\
\hline
\end{tabular}

Table 5. Assessment matrix

The majority $A$ is $\left(5\right.$, Good $\left.^{-}, 7\right)$ And the one of $B$ is $\left(6\right.$, Good $\left.^{-}, 7\right)$. As $q_{A}=q_{B}=7$, the majority rule does not make any decision and yet it is easy to verify that $A>_{m a j} B$.

\subsection{The mean-median Compromise Method (MCMM)}

This section comes from [12]

Drawing on the JM and BMC approaches, we are developing a method that can clearly and jointly address both theories and remove as many of the paradoxes presented above.

\subsubsection{Concepts and Description of MCMM}

The method we present in this article is based on both the median and the mean. This is done by dividing the rank distribution for a candidate in $2^{k}$ intervals of the same magnitude. This division determines $2^{k}+1$ grades which are the points that bound the intervals. The function returns for evaluation of a candidate the Olympic average of $2^{k_{+}} 1$ grades retained.

Is $g_{1}, g_{2}, \ldots, g_{n}$ a sequence of $\mathrm{n}$ data such as $g_{1} \geq g_{2} \geq \cdots \geq g_{n}$. The Olympic average of this data is the number:

$$
\overline{g_{o}}=\frac{1}{n-2} \sum_{i=2}^{n-1} g_{i}
$$

The Olympic average of $n$ data is therefore the arithmetic mean of these data, put aside the two extreme values [largest and smallest].

Let $N$ be the set of $n$ judges, we call the amplitude of a division the real number:

$$
\alpha=\frac{n+1}{2^{k}} \text { with } k \geq 2
$$

$k$ is a pre-set integer called bf degree of division.

$$
\begin{aligned}
M_{3} & =\left\{f^{[1 \times 1.125]}, f^{[2 \times 1.125]}, f^{[3 \times 1.125]}, f^{[4 \times 1.125]}, f^{[5 \times 1.125]}, f^{[6 \times 1.125]}, f^{[7 \times 1.125]}\right\} \\
& =\left\{f^{[1.125]}, f^{[2.25]}, f^{[3.375]}, f^{[4.5]}, f^{[5.625]}, f^{[6.75]}, f^{[7.875]}\right\}
\end{aligned}
$$




$$
=\left\{f^{1}, f^{2}, f^{3}, f^{4}, f^{5}, f^{6}, f^{7}, f^{8}\right\}=\{9,8,7,5,5,4,3\}
$$

So

$$
f^{m m}\left(A_{i}\right)=\frac{9+8+7+5+5+4+3}{7}=\frac{41}{7}=5.8
$$

\subsubsection{Tie-breaking}

When the average majority grades of two candidates are different, the one with the highest average rank is ranked before the other. The majority ranking $>_{m m}$ between two candidates evaluated by the same jury is determined by a repeated application of the majority rank:

1) We start with $k=2$

2) If $f_{k}^{m m}(A)>f_{k}^{m m}(B)$ then $A>_{m m} B$

3) If $f_{k}^{m m}(A)=f_{k}^{m m}(B)$ then the procedure is repeated for $k+1$.

Let's take the following example to illustrate this definition:

Suppose that $A$ and $B$ are evaluated by a jury 7 voters:

$$
\begin{gathered}
\alpha=\frac{7+1}{2^{2}}=\frac{8}{4}=2 \\
M_{3}=\left\{f^{2}, f^{4}, f^{6}\right\} \\
M_{2}[A]=85,73,70 \text { et } f_{2}{ }^{m m}(A)=\frac{85+73+70}{3}=\frac{228}{3}=76 \\
M_{2}[B]=85,73,72 \text { et } f_{2}^{m m}(B)=\frac{85+73+70}{3}=\frac{230}{3}=76,67 \\
f_{2}{ }^{m m}(B)>f_{2}{ }^{m n}(A)
\end{gathered}
$$

By definition, we repeat the procedure for $k=3$ and we obtain:

$$
\begin{gathered}
\alpha=\frac{7+1}{2^{3}}=\frac{8}{8} \\
M_{3}=\left\{f^{1}, f^{2}, f^{3}, f^{4}, f^{2}, f^{6}, f^{7}\right\} \\
M_{3}[A]=\{90,85,78,73,71,70,69\} \text { and } f_{3}^{m m}(A)=\frac{90+85+78+73+71+70+69}{7}=\frac{536}{7}=76.57 \\
M_{3}[B]=\{95,83,77,73,73,72,66\} \text { and } f_{3}^{m m}(A)=\frac{95+83+77+73+73+72+66}{7}=\frac{539}{7}=77 \\
f_{3}{ }^{m m}(B)=77>f_{3}^{m m}(A)=76.57 \text { Then } \mathrm{B}>_{m m} A .
\end{gathered}
$$

In this example the average majority score gives exactly the same result as the average. This is due to the fact that the set of inter-median ranks of each competitor is equal to all of his ranks.

\section{Presentation of the New Method}

The new method is also called the MVMG method.

Consider a set $\mathrm{E}$ of $\mathrm{m}$ candidates for an election, with $m \geq$ 2 and a set of voters with $s \geq 2$.

So the method is as follows:

Each of the voters uses elements of $\mathrm{P}(\mathrm{E})$ that are disjoint and whose meeting give $\mathrm{E}$, according to the following order: 1st choice, 2nd choice, 3rd choice, 4th choice. He attributes to each element of each of his subsets respectively the note $\frac{4}{4}, \frac{3}{4}, \frac{2}{4}, \frac{1}{4}$. The method consists in considering the mth root of the points of each candidate, where $\mathrm{m}$ is the number of voters. And the candidate with the highest rating is the one who represents the consensus.

\subsection{Example of 4 Candidates and 5 Voters}

Table 8. Preference matrix

\begin{tabular}{lllll}
\hline \multirow{2}{*}{$R^{(1)}=$} & 1 st choice & 2nd choice & 3rd choice & 4th choice \\
& $\left\{c_{2}, c_{4}\right\}$ & $\left\{c_{1}\right\}$ & $\left\{c_{3}\right\}$ & \\
$R^{(2)}=$ & 1 st choice & 2 nd choice & 3rd choice & 4 th choice \\
& $\left\{c_{1}\right\}$ & $\left\{c_{3}\right\}$ & $\left\{c_{4}\right\}$ & $\left\{c_{2}\right\}$ \\
$R^{(3)}=$ & 1 st choice & 2 nd choice & 3rd choice & 4 th choice \\
& $\left\{c_{3}\right\}$ & $\left\{c_{1}\right\}$ & $\left\{c_{2}, c_{4}\right\}$ & \\
$R^{(4)}=$ & 1 st choice & 2 nd choice & 3 rd choice & 4 th choice \\
& & $\left\{c_{1}\right\}$ & $\left\{c_{2}, c_{4}\right\}$ & $\left\{c_{3}\right\}$ \\
$R^{(5)}=$ & 1 st choice & 2 nd choice & 3 rd choice & 4 th choice \\
& $\left\{c_{1}\right\}$ & $\left\{c_{3}\right\}$ & & $\left\{c_{2}, c_{4}\right\}$ \\
\hline
\end{tabular}

In this example we have:

The candidate 1 has $\sqrt[5]{\frac{4 \times 3 \times 3 \times 3 \times 4}{4 \times 4 \times 4 \times 4 \times 4}}$

The candidate 2 has $\sqrt[5]{\frac{4 \times 2 \times 1 \times 2 \times 1}{4 \times 4 \times 4 \times 4 \times 4}}$ 
The candidate 3 has $\sqrt[5]{\frac{4 \times 3 \times 3 \times 2 \times 1}{4 \times 4 \times 4 \times 4 \times 4}}$

The candidate 4 has $\sqrt[5]{\frac{2 \times 2 \times 2 \times 4 \times 1}{4 \times 4 \times 4 \times 4 \times 4}}$

\subsection{Example of 5 Candidates and 9 Voters}

Table 9. Application of the new method

\begin{tabular}{llll}
\hline Candidates & grades & geometric mean & rank \\
\hline$c_{1}$ & $\frac{1}{4} \frac{1}{4} \frac{1}{4} \frac{2}{4} \frac{2}{4} \frac{3}{4} \frac{3}{4} \frac{3}{4} \frac{3}{4} \frac{4}{4}$ & $\sqrt[9]{\frac{432}{262144}}$ & $5 e$ \\
$c_{2}$ & $\frac{1}{4} \frac{1}{4} \frac{3}{4} \frac{3}{4} \frac{3}{4} \frac{3}{4} \frac{4}{4} \frac{4}{4} \frac{4}{4} \frac{4}{4}$ & $\sqrt[9]{\frac{5184}{262144}}$ & $2 e$ \\
$c_{3}$ & $\frac{1}{4} \frac{1}{4} \frac{2}{4} \frac{2}{4} \frac{2}{4} \frac{3}{4} \frac{3}{4} \frac{3}{4} \frac{3}{4}$ & $\sqrt[9]{\frac{864}{262144}}$ & $4 e$ \\
$c_{4}$ & $\frac{3}{4} \frac{3}{4} \frac{3}{4} \frac{3}{4} \frac{3}{4} \frac{3}{4} \frac{3}{4} \frac{3}{4} \frac{3}{4}$ & $\sqrt[9]{\frac{19683}{262144}}$ & $1 \mathrm{er}$ \\
$c_{5}$ & $\frac{1}{4} \frac{1}{4} \frac{2}{4} \frac{3}{4} \frac{3}{4} \frac{4}{4} \frac{4}{4} \frac{4}{4} \frac{4}{4}$ & $\sqrt[9]{\frac{4608}{262144}}$ & $3 e$ \\
\hline
\end{tabular}

\section{Proposals}

The MVMG method has the following properties:

1) Treat candidates and voters fairly. Indeed, it is at the end of the notes of all the voters that one can arrive to calculate the score of a candidate and consequently to classify all the candidates and to deduce the winner.

2 ) vote a candidate unanimously preferred by all voters. Indeed, if all the voters prefer the same candidate, it will be trivially elected

3) Designate a winner (except rare equivals). Indeed, the assessment of the different voters makes it possible to obtain the notes of all the candidates and to classify them

4) Keep the winner in the presence or absence of another candidate. if in the course of a first election, a candidate $\mathrm{x}$ is then elected in the presence of another candidate, then either $\mathrm{x}$ is elected or the other is elected

\section{Comparison with the MCMM Method}

$$
\text { For } k=3, \propto=\frac{9+1}{2^{3}}=1.25
$$

Table 10. Ranking matrix with MCMM Method.

\begin{tabular}{|c|c|c|c|c|c|c|c|c|c|}
\hline Candidates & & & & & & & & average МСМM & rank \\
\hline \multirow[b]{2}{*}{$c_{1}$} & 4 & 3 & 3 & 2 & 2 & 1 & 1 & \multirow[b]{2}{*}{164} & \multirow{2}{*}{$4 e$} \\
\hline & 4 & 4 & 4 & 4 & 4 & 4 & 4 & & \\
\hline \multirow{2}{*}{$c_{2}$} & 4 & 4 & 3 & 3 & 3 & 1 & 1 & \multirow{2}{*}{194} & \multirow{2}{*}{$3 e$} \\
\hline & 4 & 4 & 4 & 4 & 4 & 4 & 4 & & \\
\hline \multirow{2}{*}{$c_{3}$} & 4 & 3 & 3 & 2 & 2 & 1 & 1 & \multirow{2}{*}{164} & \multirow{2}{*}{$4 e$} \\
\hline & 4 & 4 & 4 & 4 & 4 & 4 & 4 & & \\
\hline$c_{4}$ & 3 & 3 & 3 & 3 & 3 & 3 & 3 & 214 & $1 \mathrm{er}$ \\
\hline \multirow{2}{*}{$c_{5}$} & 4 & 4 & 4 & 3 & 3 & 1 & 1 & \multirow[t]{2}{*}{204} & \multirow[t]{2}{*}{$2 e r$} \\
\hline & 4 & 4 & 4 & 4 & 4 & 4 & 4 & & \\
\hline
\end{tabular}

We can easily see that candidate 4 is still the first, but we do not have exactly the same rank as the MVMG. This is because the MCMM method incorporates the arithmetic mean which, given its compensatory effect, may contribute to changing rank.

\section{Comparison with the Majority Judgment}

Table 11. Ranking matrix with the Majority Judgment.

\begin{tabular}{|c|c|c|c|c|c|c|c|c|c|c|c|}
\hline Candidates & & & & & & & & & & average judgment & rank \\
\hline \multirow[b]{2}{*}{$c_{1}$} & 1 & 1 & 1 & 2 & 2 & 3 & 3 & 3 & 4 & 2 & \multirow{2}{*}{$4 e$} \\
\hline & 4 & 4 & 4 & 4 & 4 & 4 & 4 & 4 & 4 & 4 & \\
\hline \multirow{2}{*}{$c_{2}$} & 1 & 1 & 3 & 3 & 3 & 3 & 4 & 4 & 4 & 3 & \multirow{2}{*}{$1 e r$} \\
\hline & 4 & 4 & 4 & 4 & 4 & 4 & 4 & 4 & 4 & 4 & \\
\hline \multirow{2}{*}{$C_{3}$} & 1 & 1 & 2 & 2 & 2 & 3 & 3 & 3 & 4 & 2 & \multirow{2}{*}{$4 e$} \\
\hline & 4 & 4 & 4 & 4 & 4 & 4 & 4 & 4 & 4 & 4 & \\
\hline$C_{4}$ & 3 & 3 & 3 & 3 & 3 & 3 & 3 & 3 & 3 & 3 & $1 \mathrm{er}$ \\
\hline \multirow{2}{*}{$C_{5}$} & 1 & 1 & 2 & 3 & 3 & 4 & 4 & 4 & 4 & 3 & \multirow{2}{*}{$1 e r$} \\
\hline & 4 & 4 & 4 & 4 & 4 & 4 & 4 & 4 & 4 & 4 & \\
\hline
\end{tabular}

We see that there are three candidates first exaquo which include the candidate 4 and the others are also exaequo with the last position. You have to make a tie-beak to decide between them.
As a result we can conclude that the MVMG gives good results. While the MCMM methods and majority judgment often give a tie and sometimes require repeated repetition of the method to determine the candidates. 


\section{Discussion and Perspectives}

The aggregation of individual preferences into a collective preference is conceived by means of an aggregation function, which are generally mathematical formulas or functions of social choice. This formula makes it possible to classify the candidates to an election through the appreciation of the voters on these last ones. The determination of a social choice function with good properties makes it possible to transform the individual choice into a choice representing the general interest which is the desire sought. The geometric mean is a method with good properties because it does not compensate for strong criteria by weak ones like the arithmetic mean which is widely used in many voting systems. Better still, if a candidate has very low scores and others very strong this is felt through the calculation of the arithmetic mean. It favors candidates who do not have very weak scores and who are not very dispersed. Voting by assent being well appreciated in the literature because of its interesting properties, its combination with the average Geometric allowed the development of the MVMG method which also fulfills good properties. We have therefore brought to the literature a good voting system in the sense that its use does not give controversial results. Certainly it could engender some limits as any function of social choice according to [1], the choice of a voting method shapes the democracy in which we live. A "good" voting system, fulfilling all the desirable properties, does not exist: one has to be satisfied with a satisfactory vote [2].

In addition to [4], it appears that the experimental results confirm that, for given preferences, changing the voting system is likely to change the outcome of the election. Similarly in [5], several recent studies (Blais, Laslier, Laurent, Sauger and Van der Straeten, 2007; Van der Straeten, Laslier, Sauger and Blais, 2010; Igersheim, Baujard, Gavrel, Laslier and Lebon, 2015) also highlight the fact that Aggregate results differ from one voting system to another. Will future research permit the use of geometric mean in metric procedures?

\section{References}

[1] Antoinette Baujard et al: vote par approbation, vote par note, une expérimentation lors de l'élection présidentielle du 22 avril 2012, revue économique 2013/2-vol. 64 pages 345 à 356 .

[2] Antoinette BAUJARD, Herrade IGERSHEIM: Expérimentation $\mathrm{du}$ vote par note et du vote par approbation de l'élection présidentielle française du 22 avril 2007, Rapport final, Antoinette BAUJARD, CREM, Université de Caen-BasseNormandie; Herrade IGERSHEIM, CNRS et CEPERC,
Université de Provence-Aix-Marseille I, Rapport public du Centre dŠAnalyse Stratégique. 2007. <halshs-00337290> 2007.

[3] Hatem SMAOUI, Dominique LEPELLEY: Le système de vote à trois niveaux: Etude d'un nouveau mode de scrutin, Dalloz «Revue d'économie politique» 2013, 6 vol. 123, pages 827 à 850 ISSN 0373-2630.

[4] Herrade IGERSHEIM, Antoinette BAUJARD, Jean-François LASLIER: La question du vote. Expérimentations en laboratoire et In Situ., Working paper GATE 2016-33. 2016. $<$ halshs01402275>.

[5] Herrade IGERSHEIM, Antoinette BAJARD, Jean-François LASLIER: L'actualité économique, Revue d'analyse économique, vol. 92, no1-2, mars-juin 2016.

[6] Jorge GONZALEZ SUITT, Axel GUYON, Thibault HENNION, Rida LARAKI, Xavier STARKLOFF, Sophie THIBAULT, Benjamin FAVREAU: Vers un système de vote plus juste?, cahier no 2014-20, septembre 2014.

[7] Khaled JABEUR, Jean-Marc MARTEL: Une méthode de choix collectif à partir de systèmes relationnels de préférences (S. R. P.), ISBN-2-89524-202-X, 04-2004.

[8] Michel BALINSKI, Rida LARAKI, Jugement majoritaire vs. vote majoritaire, cahier no 2012-37, Département d'économétrie, Route de Saclay, 91128 PALAISEAU CEDEX (33) 169333033.

[9] Michel TRUCHON: Choix social et comités de sélection: le cas du patinage artistique, Université Laval CIRANO, CIRPEE Novembre 2002, ISSN 1701-9990, 2002 RB -02.

[10] Patrick BLANCHENAY: Parodoxes de vote et modes de scrutin en France, Ecole des hautes études commerciales Majeure économie, Mai 2004, sous la direction de Hervé CRES.

[11] Ruffin-Benoît M. NGOIE, Zoinabo Savadogo, Berthold E.-L. ULUNGU: Median and average as tools for measuring, electing and Ranking: New propects, Fundamental Journal of Mathematics and Mathematical Sciences, vol. 1, Issue 1, pages 9-30, 2014.

[12] M. Balinski \& R. Laraki (2010). Majority Judgment. Measuring, ranking and Electing MIT. ISBN 978-0-26201513-4

[13] Balinski M. and R. Laraki (2007) «Election by Majority Judgment: Experimental Evidence». Cahier du Laboratoire d'Econométrie de l'Ecole Polytechnique 2007-28.

[14] Manzoor Ahmed Zahid (2012). A new framework for elections. Shaker Publishing.

[15] Hillinger, C (2004a). On the possibility of democracy and rational collective choice. Discussion Paper 2004- 21, University of Munich. 